\title{
Simple Crack Models Explain Deformation Induced by Subduction Zone Megathrust Earthquakes
}

\author{
by Shiqing Xu, Eiichi Fukuyama, Han Yue, and Jean-Paul Ampuero
}

\begin{abstract}
Following the 2010 Maule and 2011 Tohoku earthquakes, many studies have examined the relation between megathrust earthquakes and subsequent deformation. Here, we apply simple models based on mode II shear cracks, including approximated effects of the free surface to study induced deformation during coseismic and early postseismic stages. We distinguish between buried and surface ruptures represented by a full-crack and a half-crack model, respectively. We adopt an analogybased approach to interpret the half-crack model from well-known results of the full-crack model, which is also validated by our numerical simulations. With transferable knowledge between the two models, we provide easy ways to understand (1) the contrasting deformation patterns in the frontal wedge of the overriding plate between buried ruptures and surface ruptures, (2) the correlation between triggered outer-rise normal faulting and surface ruptures, and (3) the similar deformation patterns for both buried and surface ruptures toward the down-dip end, with a preference for normal faulting in the overriding plate and for reverse faulting in the subducting plate. These model outcomes are consistent with several recent observations on aftershocks and veins in a paleoaccretionary wedge. We further investigate some important transient features during rupture propagation which show that a transition from compressional to extensional deformation in the frontal wedge of the overriding plate is possible even during a single rupture event. Our work provides alternative views for understanding various aspects of subduction zone megathrust earthquakes and raises the issue of important transient features that were typically ignored in previous studies.
\end{abstract}

\section{Introduction}

Several recent great subduction zone earthquakes, such as the $2010 M_{\mathrm{w}} 8.8$ Maule earthquake in Chile and the 2011 $M_{\mathrm{w}} 9.0$ Tohoku earthquake in Japan, have greatly sharpened our view of various aspects of earthquake physics, including foreshock activity and its influence on mainshock nucleation, depth-dependent earthquake source properties, and structural and rheological control on coseismic and postseismic slip (Ando and Imanishi, 2011; Meng et al., 2011; Lay et al., 2012; Moreno et al., 2012; Sun and Wang, 2015). In particular, changes in seismicity patterns have shed light on the spatiotemporal evolution of the stress state around subducting plate boundaries. A dramatic change in focal mechanisms of shallow intraplate seismicity from reverse to normal was observed following the 2011 Tohoku earthquake and was attributed to rotation of the maximum compressive stress $\sigma_{1}$ toward vertical, due to nearly complete coseismic stress drop (Hasegawa et al., 2011; Hardebeck, 2012). Following the 2010 Maule earthquake, the focal mechanisms of aftershocks were found to depend on their along-dip location relative to the local slip centroid: a sequence of normal-type aftershocks occurred above the down-dip end of the northern slip segment, whereas many reverse-type aftershocks occurred above the up-dip end of the central slip segment (Farías et al., 2011; Melnick et al., 2012; Li et al., 2014; Yue et al., 2014).

Several models have been applied to understand deformation induced by megathrust earthquakes. One is the stressdrop model developed by Hardebeck and Hauksson (2001), which was employed by Hasegawa et al. (2011) for the 2011 Tohoku earthquake. Although this model reasonably explains the normal-type aftershocks in the overriding plate and the shallow part of the subducting plate, it fails to explain the asymmetric aftershock pattern across the plate interface, roughly from the geometric center of the source region all the way toward its down-dip end (Hardebeck, 2012; Hasegawa et al., 2012). This latter feature presumably reflects asymmetry of stress perturbations on different sides of the mainshock plane, which is not captured by the stress-drop model because it considers a uniform deviatoric stress perturbation in the surrounding medium. Moreover, to explain a towardvertical rotation of $\sigma_{1}$ axis that is essential for triggering normal faulting, the stress-drop model requires an initially high inclination of $\sigma_{1}$ axis $\left(>45^{\circ}\right)$ relative to the plate interface 
before the mainshock. Although this condition seems to be satisfied in many subduction plate boundaries, exceptions do exist, such as the Japan Trench region (Hardebeck, 2015) that hosted the 2011 Tohoku earthquake. Given the inconsistency on the estimated mean value of premainshock stress orientation with respect to $45^{\circ}$ between Hardebeck (2012) and Hardebeck (2015) for the Japan Trench region, it is therefore necessary to explore whether the requirement on premainshock stress orientation can be loosened if ignored factors (e.g., volumetric deformation) are taken into account.

Another model is the dynamic critical taper model developed by Wang and $\mathrm{Hu}$ (2006), which relates the stress state in the overriding plate to an adjustable basal friction during different phases of seismic cycles. In each phase, after assigning an appropriate basal friction to a selected subduction zone segment, the model still solves the problem under quasi-static equilibrium. A limitation of this model is that it only uses the steady-state value of basal friction and does not take into account any transient effect during a given phase. For example, it assumes a (steady state) velocity-strengthening friction along the most seaward part of the plate interface. Such assumption may work well for understanding compressional deformation seaward of buried megathrusts, as for the central slip segment of the 2010 Maule earthquake (Melnick et al., 2012; Yue et al., 2014), but it would have a difficulty in explaining rupture to the trench and coexistence of both compressional and extensional features in the frontal wedge, as observed for the 2011 Tohoku earthquake (Koge et al., 2014).

Alternatively, the coulomb stress change model (King et al., 1994; Lin and Stein, 2004) has been widely used by many researchers, due to the computational power to handle many realistic complexities (fault segmentation, free surface, etc.). Application of the static version of this model requires an input slip model (i.e., a dislocation model with prescribed slip distribution) to calculate stress perturbations imposed from the slipped region to the surrounding medium. This has led to the recognition of several important factors influencing the deformation pattern in subduction zones. These factors include whether the main rupture breaks the surface (Lin and Stein, 2004) or displays a large shallow slip (Hasegawa et al., 2012), individual or combined effects of shear stress change and normal stress change (Yang et al., 2013), contributions from shallow seismic slip and deep aseismic slip (Gardi et al., 2006), along-dip location with respect to local slip centroid (Li et al., 2014), and the type of preexisting faulting in relation to the magnitude of stress perturbation (Imanishi et al., 2012). Despite great success, in practice, the initial setup (fault geometry, slip distribution, boundary condition, etc.) for the slip model could be quite complex, reflecting diverse constraints (e.g., resolution limits, a priori assumptions) in slip inversions or actual heterogeneous features in subduction zones (Tajima et al., 2013; Hicks et al., 2014; Brown et al., 2015). As a result, the subsequent investigation on megathrust-induced deformation often involves complicated computations. A deep understanding of the computational results, such as a general connection between coulomb stress change distribution and displacement distribution on each side of the fault (not just slip distribution on the fault), however, is still incomplete. This in turn may limit our understanding of megathrust earthquakes.

To advance our fundamental understanding of subduction zone megathrust earthquakes, we seek simple models that can better illuminate their first-order control on the subsequent deformation. We apply well-known theoretical results based on mode II shear cracks, accounting for effects of the free surface, to analyze the perturbed stress field of megathrust earthquakes, in particular its variability in the along-dip direction. Our analysis leads to a classification based on two end members: buried ruptures described by a full-crack model and surface ruptures described by a halfcrack model. Although the issue of deformation patterns caused by buried versus surface ruptures has already been explored before, also using simple dislocation models (Okada, 2003; Lin and Stein, 2004), much focus was put on the differences between the two, rather than on their interrelationship. In this study, based on reasonable assumptions that are later validated numerically, we are able to interpret certain features of surface ruptures by referring to well-known results of buried ruptures. Surprisingly, such an analogybased simple approach works quite well, as supported by several observational results on aftershocks and veins in a paleoaccretionary wedge. In this way, we obtain a better understanding, with transferable knowledge between the two general classes of megathrust earthquakes. We also examine important transient features of the stress field during rupture propagation, the signatures of which may be preserved despite overprinting by later deformation. Finally, we discuss some important implications from our models by comparing them with other fault models.

\section{Full-Crack and Half-Crack Conceptual Models}

We focus on two conceptual end-member crack models that describe two general classes of slip distribution of megathrust ruptures. The full-crack model (Fig. 1a) represents buried ruptures, bounded at both ends by barriers. Its slip profile has a semielliptical shape that tapers to zero in both directions. As long as the considered rupture is buried at a depth not very close to the surface, we can reasonably assume that the partitioned fault-parallel displacements on the two sides of the crack share a similar shape (as one half of the slip), but with opposite polarities. Several fundamental properties of such a mode II full crack are already well known (Pollard and Segall, 1987, and references therein): (1) $\sigma_{1}$ is inclined gently relative to the crack in the compressional quadrants (I and III in Fig. 1a), and inclined steeply in the extensional quadrants (II and IV in Fig. 1a); (2) the shear motion causes the nearby displacements (brown arrows in Fig. 1a) to rotate away from the crack in the compressional quadrants (I and III in Fig. 1a), and toward the crack in the extensional quadrants (II and IV in Fig. 1a). It should be noted that properties (1) and (2) are closely related: the rotation of 

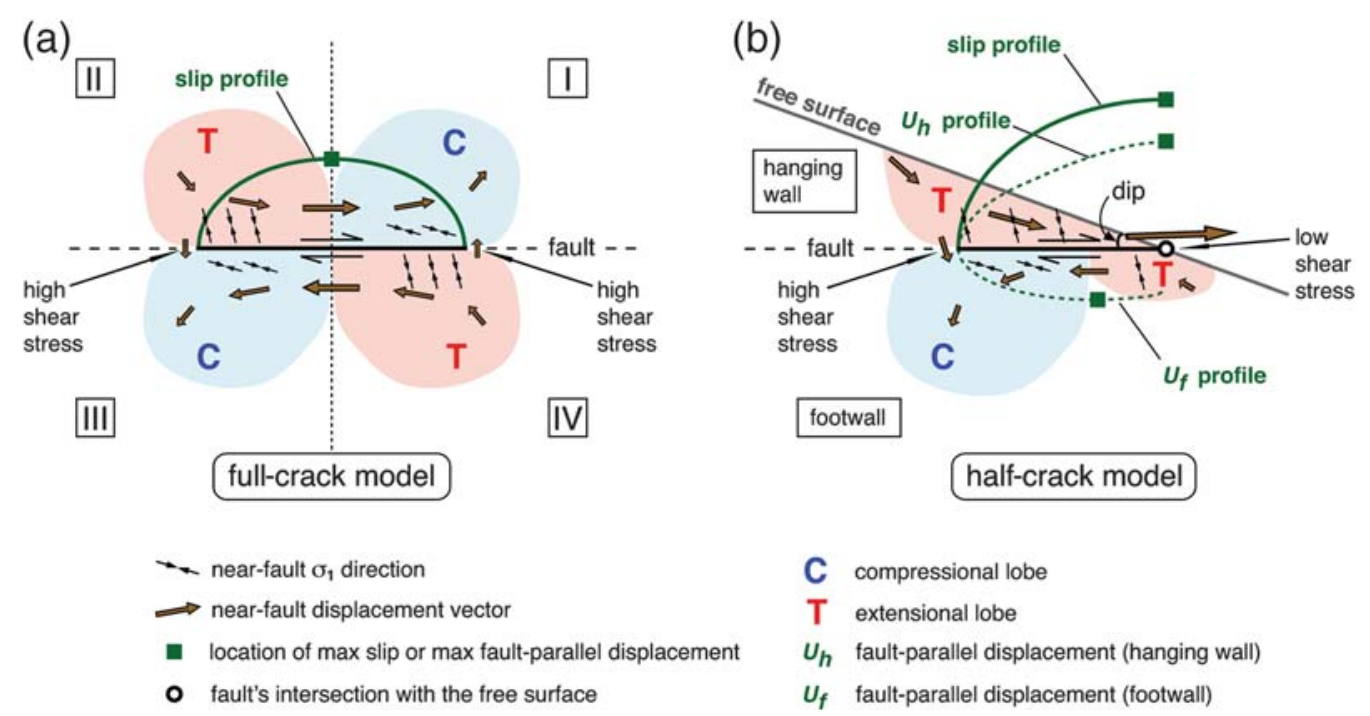

Figure 1. The principal axis $\sigma_{1}$ (pairs of arrows) and displacement vector (thick brown arrows) near mode II (a) full crack and (b) half crack. The surrounding space in (a) is divided into four quadrants, marked by Roman numbers I-IV. The half space in (b) is divided into two halves marked by the hanging wall and footwall. The solid green curve shows the slip profile for each crack model, whereas the dashed green curve in (b) shows the fault-parallel displacement profile on the hanging wall $\left(U_{h}\right)$ and footwall $\left(U_{f}\right)$. The green square marks the location of maximum slip or maximum fault-parallel displacement. $\mathrm{C}$ and $\mathrm{T}$ denote regions experiencing compressional and extensional stress change, respectively. Note the features shown in both (a) and (b) correspond to the final static state.

the fault plane produced by the antisymmetric fault-normal displacement with respect to the vertical axis and the normal strain produced by the spatial gradient of fault-parallel displacement can be used to understand the volumetric deformation and the principal stress orientation in each quadrant. It should also be noted that, how well properties (1) and (2) are verified depends on the observational scale relative to the crack size and the magnitude of stress drop relative to that of the background stress. Because our targets are megathrust earthquakes with potential to produce large or even complete stress drop, and our focus is on the near-field deformation, in this study we mainly use the near-fault (at scales up to the rupture dimension) features dominated by mainshock-induced deformation for discussion, unless mentioned otherwise. Although property (1) presents the distorted stress orientation in relation to volumetric deformation near a mode II shear crack, whether off-fault failure can be induced should only be checked by evaluating appropriate failure criteria and by comparison with observations. Indeed, consistent secondary fractures tracking appropriate stress trajectories on each side of the crack, particularly near the tip region, have been reported, including mode I wing cracks, mode II synthetic and antithetic shear branches (Kim et al., 2004; Blenkinsop, 2008; Misra et al., 2009; Xu and Ben-Zion, 2013; Anders et al., 2014). In the context of seismicity triggered by buried slip along a reverse fault, consistency has also been reached: reverse and normal faulting is more favored in the compressional and extensional quadrant(s), respectively (Lin and Stein, 2004; Cortés-Aranda et al., 2015).

A somewhat less-known model is the half-crack model (Fig. 1b), on which we expand below to clarify several important points that have not been well summarized in the lit- erature. This model represents surface-breaking ruptures, the up-dip end of which is constrained by the free surface instead of a barrier (note that the features shown in Fig. 1b correspond to the final static state). Its slip profile has a quarterelliptical shape that resembles one-half of the slip profile of the full crack. Its maximum slip is located at the up-dip end, that is, where the fault intersects the free surface. Theoretical and numerical backgrounds for this half-crack model can be found in related studies (Rudnicki and Wu, 1995; Oglesby et al., 1998; Geist and Dmowska, 1999), whereas only in this study is this model systematically applied for understanding deformation induced by surface-breaking megathrust earthquakes. An intermediate type of rupture, characterized by incipient slip at the surface and major slip at depth, is not considered in this study.

The generation of a half-crack-like slip profile does not necessarily require high stress drop at shallow depth (Huang et al., 2014). Moreover, large shallow slip does not require frictional weakening of the megathrust all the way to the surface (Kozdon and Dunham, 2013). The free surface has at least three different effects that promote large shallow slip along a thrust fault (Oglesby et al., 1998; Huang et al., 2012; Kozdon and Dunham, 2013; Xu, Fukuyama, et al., 2015): permanent unclamping of the fault behind the rupture front, additional stress drop caused by reflected waves, and small resistance to slip at the fault's intersection with the surface (due to the small magnitudes of initial stress and cohesion compared to the dynamic stress changes). Regarding the third effect, sudden amplification of fault slip is often observed as the rupture just breaks the free surface. Once broken, the free surface also allows continued slip and a backward-propagating re-rupture phase, until a healing front emitted from elsewhere 
(e.g., the down-dip end) finally arrives. These two features have been reported in numerical simulations (Huang et al., 2012; Kozdon and Dunham, 2013; Xu, Fukuyama, et al., 2015), in finite-fault inversions for the 2011 Tohoku earthquake (Ide et al., 2011; Suzuki et al., 2011), and in labquakes (McLaskey et al., 2015). Moreover, they provide new insight, beyond a kinematic consideration of slow rupture speed, into the long source duration for surface-breaking ruptures (Lay et al., 2012). If unfavorable conditions dominate over those effects caused by the free surface, such as low initial stress or frictional strengthening at shallow depth, the rupture may barely reach the surface but still have its major slip at depth. This type of ruptures is intermediate between the full-crack and half-crack models. Although we do not consider this case further here, some studies imply that it may be grouped into buried ruptures (full crack) based on the resulting volumetric deformation (Davis et al., 2015, fig. 9).

The genetic connection in slip profiles between the fullcrack model (Fig. 1a) and the half-crack model (Fig. 1b) suggests that some pre-existing knowledge of the former can be naturally transferred to the latter. In fact, a similar idea has already been applied for mode III ruptures along vertical strike-slip faults (Pollard and Segall, 1987). However, some extra care should be taken for the mode II case, because slip partitioning is usually not symmetric between the two sides of a surface-breaking reverse fault, especially when the dip angle is $<45^{\circ}$. Illustrative examples of asymmetric displacements produced by a dip-slip fault with uniform slip can be found in figure 6 of Okada (2003), whereas in the following we refer to results with nonuniform slip more relevant to crack models. We remind that an overall agreement can be reached between a uniform slip model and the shallow slip part of a half-crack model, such as an increasing (decreasing) trend in hanging-wall (footwall) displacement magnitude toward the surface. As a result, the requirement on the exact location of maximum slip (e.g., whether at the up-dip end or deeper) can be loosened while still retaining the key deformation features partitioned on each side of the fault.

Previous results on a surface-breaking reverse fault dipping at $30^{\circ}$ (Oglesby et al., 1998, fig 4) showed that more displacement is systematically partitioned on the more compliant (with less mass) hanging-wall side, whose profile shows a monotonic trend that can be still fitted with a quarter-ellipse (e.g., see the dashed green curve marked as $U_{h}$ in Fig. 1b, which indicates fault-parallel extension over a spatial extent comparable to the rupture dimension). This suggests that the deformation on the hanging-wall side of the half crack (Fig. 1b) can be represented approximately by the quadrant II of the full crack (Fig. 1a). As for the stiffer (with more mass) footwall side, the maximum displacement is located with some distance from the free surface, to compensate the larger displacement on the hanging wall near the surface (the more compliant hanging wall needs to deform more to sustain a force balance against the stiffer footwall, see Oglesby et al., 1998). As a result, the partitioned displacement on the footwall tapers from its maximum toward both up-dip and down-dip directions (e.g., see the dashed green curve marked as $U_{f}$ in Fig. 1b, which indicates faultparallel extension in the shallow part and compression in the deep part). This suggests that the deformation on the footwall side of the half crack (Fig. 1b) can be represented approximately by the quadrants III and IV of the full crack (Fig. 1a), despite that in the half crack $U_{f}$ does not taper to zero at the up-dip end. As will be shown by our numerical simulations with an even shallower dip angle $\left(10^{\circ}\right)$ to better match subduction zones, these approximations made in the half-crack model by referring to certain parts of the full-crack model are reasonable. We therefore use these references combined with the well-known results of the full-crack model to understand the deformation pattern induced by surface ruptures.

\section{Setup for Numerical Simulations}

To examine the validity of the conceptual crack models, particularly the analogy between the half-crack model and parts of the full-crack model in subduction zones, we conduct numerical simulations along a shallowly dipping $\left(10^{\circ}\right)$ reverse fault (Fig. 2) using a 2D spectral element code SEM2DPACK (Ampuero, 2002). The overall model setup follows that in $\mathrm{Xu}, \mathrm{Fu}-$ kuyama, et al. (2015) for half-space, whereas in this study only a single fault (the megathrust) with a total length of $121.9 \mathrm{~km}$ is considered (see the inclined black line in Fig. 2a). Quadrilateral meshes with an average node spacing of $\sim 50 \mathrm{~m}$ are used to provide fine enough resolution surrounding the fault, and a time step of $\sim 2 \times 10^{-4} \mathrm{~s}$ is assumed to ensure stability of dynamic rupture simulations. Material properties for the numerical simulations are shear modulus $\mu=32.4 \mathrm{GPa}, P$ wavespeed $c_{P}=6000 \mathrm{~m} / \mathrm{s}, S$-wavespeed $c_{S}=3464 \mathrm{~m} / \mathrm{s}$, and rock density $\rho=2700 \mathrm{~kg} / \mathrm{m}^{3}$. Rupture typically starts at a $90-\mathrm{km}$ down-dip distance from the surface (see the star in Fig. 2a) under a time-weakening nucleation procedure. Outside the predefined nucleation zone, the fault is governed by slip-weakening friction and is bounded by a barrier (a zone with high cohesion, denoted by the triangle in Fig. 2a) in the down-dip direction. In the full-crack model, another barrier is inserted in the up-dip direction. More details can be found in the caption of Figure 2 and in Xu, Fukuyama, et al. (2015). General consistency between our conceptual crack models and numerical results along a shallowly dipping fault can be found by the shown figures in the Model Application to Dynamic Rupture and Observational Results section. We remind that the main purpose here is to provide reference numerical results useful for validating the general features predicted by the conceptual models. We leave the detailed sensitivity tests on model parameters for future studies.

\section{Model Application to Dynamic Rupture and Observational Results}

Here, we compare the full-crack and half-crack models to dynamic rupture simulations and previous observational studies of megathrust earthquakes in subduction zones to de- 
(a)

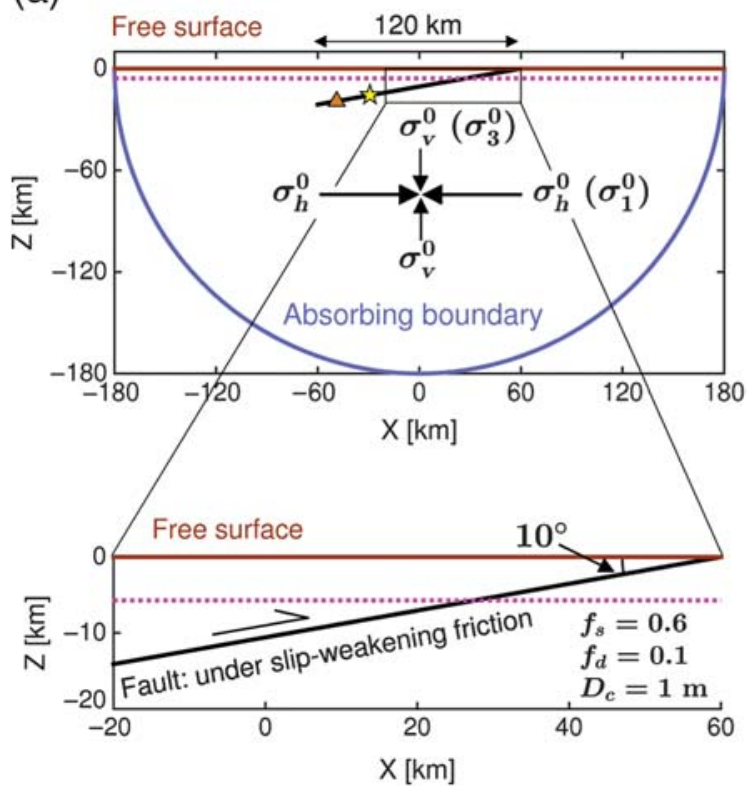

(b)

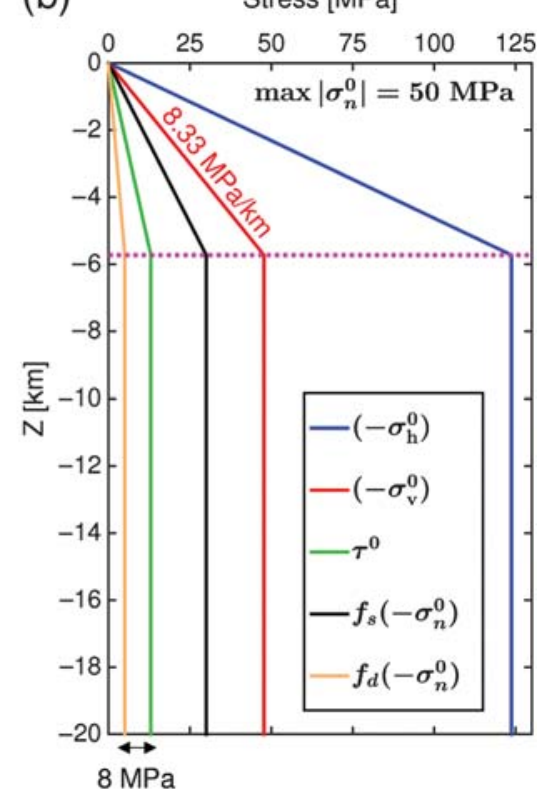

Figure 2. Model setup for the numerical simulations along a shallowly dipping $\left(10^{\circ}\right)$ reverse fault. (a) Global and local view of the computational domain. $\sigma_{h}^{0}$ and $\sigma_{v}^{0}$ denote the initial horizontal and vertical normal stresses (negative in compression), which coincide with the initial maximum and minimum compressive stresses $\sigma_{1}^{0}$ and $\sigma_{3}^{0}$, respectively. Star marker indicates the hypocenter of the rupture. A barrier (denoted by the triangle, modeled with raised cohesion from 0 to $100 \mathrm{MPa}$ over a $200 \mathrm{~m}$ patch) is commonly set in the down-dip direction for all the simulations, whereas such a barrier is only inserted in the up-dip direction for generating buried ruptures. A linear slip-weakening friction law is assumed along the fault, with a static friction coefficient $f_{s}=0.6$, a dynamic friction coefficient $f_{d}=0.1$, and a slip-weakening distance $D_{c}=1 \mathrm{~m}$. (b) Along-depth distribution of various initial stress components. $\tau^{0}$ and $\sigma_{n}^{0}$ represent the initial shear and normal stresses resolved onto the fault, respectively. Note in this study, all the initial stress components and the value of $D_{c}$ have been reduced to halves of those assumed in Xu, Fukuyama, et al. (2015). Nevertheless, the general features remain unchanged and can always be discussed using normalized quantities. The dotted line indicates the depth at which initial stresses start to get saturated.

velop a first-order understanding of their induced deformation patterns. Following each simulated rupture scenario, we still use the concept of coulomb stress change or total coulomb stress to numerically evaluate the failure tendency at hypothetic receiver faults. However, these exercises are performed merely to validate our conceptual models. Once validated, the conceptual models can be applied more broadly without conducting additional computations, and the underlying mechanisms may be more easily understood by referring to transferable knowledge from pre-existing models.

The deformation in the shallow part of the overriding plate induced by buried and surface ruptures is very different. For buried ruptures, for which the quadrant I of the full-crack model (Fig. 1a) is applicable, the frontal wedge of the overriding plate is under compressional stress change and increased basal shear stress (Figs. 1a and 3), which favors reverse faulting along bedding planes or splay faults (Fig. 4a,b) while suppresses normal faulting (Fig. 4c,d). The nearly identical coulomb stress patterns between conjugate planes favoring reverse faulting at gentle dips (Fig. 4a,b) confirm that the induced maximum compression is horizontal or subhorizontal in the frontal wedge following a buried rupture (Fig. 3a). The fullcrack model, together with several other studies allowing variability in detailed slip profile (type $\mathrm{C}$ earthquake in $\mathrm{Li}$ et al., 2014; case a in fig. 9 of Davis et al., 2015; fig. 17 of
Xu, Fukuyama, et al., 2015), explains the occurrence of reverse-type aftershocks observed near the up-dip end of the central segment of the 2010 Maule earthquake, including the reactivation of a seaward-dipping splay fault (Melnick et al., 2012; Yue et al., 2014). In contrast, for surface ruptures, for which the half-crack model (Fig. 1b) by referring to the quadrant II of the full-crack model (Fig. 1a) is applicable, much of the frontal wedge is under extensional stress change and reduced basal shear stress (Figs. 1b and 5), which suppresses reverse faulting (Fig. 6a,b) but favors normal faulting (Fig. 6c,d), especially at shallow depth (Fig. 7) at which even moderate fault rotation and fault-parallel extension can reverse the state set by the low-magnitude initial compressive stress. The nearly identical coulomb stress patterns between conjugate planes favoring normal faulting at steep dips (Fig. 6c,d) confirm that the induced maximum compression is vertical or subvertical in the frontal wedge following a surface rupture (Fig. 5a). Such contrasting volumetric deformation in the shallow part of the overriding plate has also been numerically verified elsewhere (Lin and Stein, 2004; Davis et al., 2015, fig 9), but a thorough interpretation by referring to well-known results of a pre-existing model (the full-crack model) is provided only in the present study. A numerical example of normal slip triggered on a splay fault by a surface megathrust rupture can be found in figure 16 of $\mathrm{Xu}$, 

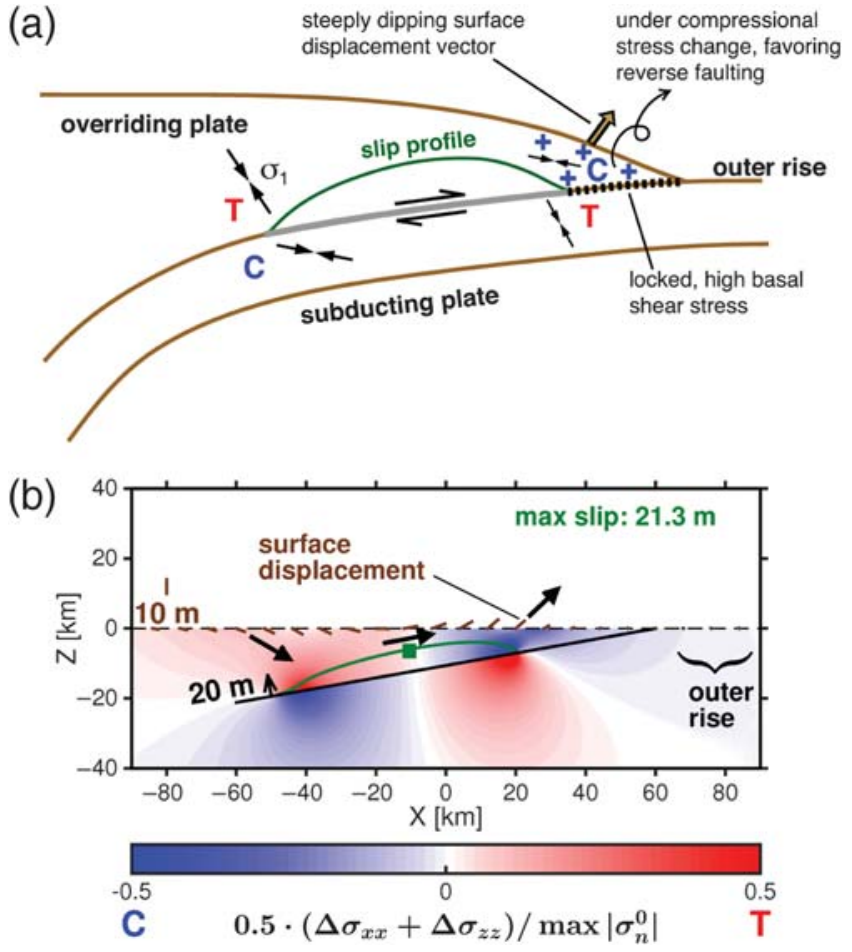

Figure 3. (a) Key deformation features induced by a buried rupture, described by a full-crack model. (b) The numerically simulated slip distribution (solid green curve) on the fault (solid black line), mean stress change, and surface displacement (brown bars). The green square marks the location of maximum slip. Thick black arrows highlight the surface displacement directions on selected portions (from right to left): above the up-dip end, central portion, and down-dip end of the buried rupture. Additional numerical results on coulomb stress change resolved onto various planes can be found in Figure 4.

Fukuyama, et al. (2015). The half-crack model is consistent with the widespread normal-type aftershocks above the large slip region of the 2011 Tohoku earthquake (Hasegawa et al., 2012) and similar aftershock patterns following some tsunami earthquakes (Y. Yagi, personal comm., 2015).

In addition to the mechanism of shallow aftershocks, seafloor displacement (and its effect on tsunami generation) may be used to distinguish surface ruptures from buried ruptures along a shallowly dipping reverse fault. The surface displacement in the frontal wedge predicted by our elastic model is seaward and upward and has a steeper angle than the dip of the plate interface for buried ruptures (Fig. 3) but is almost parallel to the plate interface for surface ruptures (Fig. 5). Such contrasting surface displacement directions reflect the differences in the basal boundary condition and the resulting slip gradient (more strictly speaking, the gradient of the partitioned upper-plate displacement) to the up-dip direction between buried and surface ruptures. On the other hand, the surface displacement direction above the up-dip portion of a surface rupture (Fig. 5b) does resemble the displacement direction above the central portion of a buried rupture (Fig. 3b). Such coincidence, along with other similarities in the exten- sional deformation and the monotonically increasing displacement toward the up-dip direction, validates our earlier approximation in conceptual models by treating the hanging wall of the half-crack model (Fig. 1b) and the quadrant II of the full-crack model (Fig. 1a) as analogous. Therefore, although the difference in up-dip surface displacements between buried and surface ruptures has long been recognized in the literature (Satake and Tanioka, 1999; Okada, 2003), the view here, separately referring to the tip and central portions of the full-crack model, is new. Despite a more horizontal displacement direction, surface ruptures may still be more efficient than buried ruptures in exciting tsunamis, because of their larger absolute amount of uplift (compare Fig. 5b with Fig. 3b). Surface ruptures can produce larger slip (by a factor of 2 or more) than buried ruptures, even with the same stress drop and source dimension (Rudnicki and Wu, 1995; Geist and Dmowska, 1999, and references therein). The larger absolute slip may dominate over the effect of a more horizontal displacement direction, leading to huge tsunami excitation by surface ruptures. Such scenario was clearly evidenced by the 2011 Tohoku earthquake and its excited tsunami, with additional contribution from the translation of a sloped seafloor (Ito et al., 2011).

Some insights on buried and surface ruptures can also be obtained in the shallow part of the subducting plate. First of all, despite the large shallow slip near the trench following a surface rupture, the partitioned displacement on the footwall side $U_{f}$ has a decreasing trend in magnitude toward the trench (Fig. 5b). This feature, together with the induced extensional lobe and the slightly inclined (i.e., not fault parallel) displacement vector in the shallow part of the subducting plate (Fig. 5b), validates our earlier approximation by treating the shallow footwall of the half-crack model (Fig. 1b) and the quadrant IV of the full-crack model (Fig. 1a) as analogous. A supporting observational result can be found by the normal-type aftershocks in the subducting plate, near the up-dip end of the 2011 Tohoku earthquake (Obana et al., 2013). Second, although both buried ruptures (Fig. 3b) and surface ruptures (Fig. 5b) can induce an extensional lobe in the shallow part of the subducting plate, only with surface ruptures can the lobe and its associated tendency for favoring normal faulting (Fig. 6c,d) cover a significant portion of the outer rise. This explains the correlation between triggered outer-rise normal faulting and adjacent slip patch reaching the trench, as evidenced by the northern and southern sections of the 2010 Maule earthquake (Yue et al., 2014). More observational examples, including the 2011 Tohoku earthquake and some tsunami earthquakes, can be found in Lay (2015).

Unlike the up-dip end, the deformation near the downdip end induced by buried and surface ruptures is not significantly different. Both the full-crack and half-crack models predict extensional deformation, with a steeply inclined $\sigma_{1}$ axis in the overriding plate (Figs. 1, 3, 4c,d, 5, and 6c,d) and compressional deformation associated with a gently inclined $\sigma_{1}$ axis in the subducting plate (Figs. 1, 3, 4a,b, 5, and 6a,b). Such similarity to the down-dip direction also explains why 

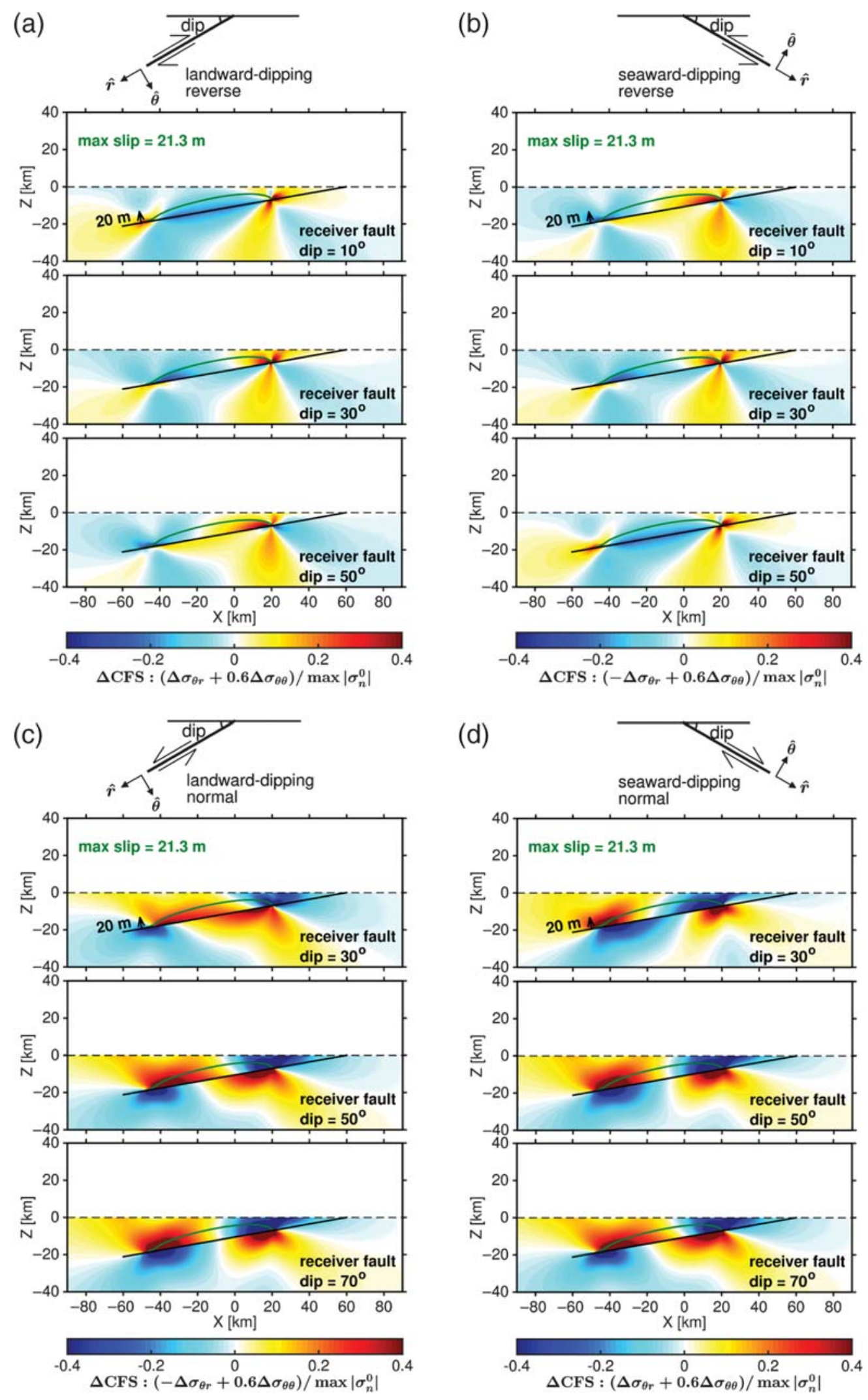

Figure 4. Distribution of normalized coulomb failure stress change $(\Delta \mathrm{CFS})$ resolved onto several (a, c) landward-dipping and (b, d) seaward-dipping planes, following a buried rupture as illustrated in Figure 3. The top schematic plots show the configurations of the receiver fault plane, with $\hat{\boldsymbol{r}}$ and $\hat{\boldsymbol{\theta}}$ being the unit vectors parallel and perpendicular to the receiver fault, respectively. Sign of shear stress is chosen to favor reverse faulting in (a) and (b) and normal faulting in (c) and (d). Green curves in the plots below show the slip distribution along the fault. An effective friction coefficient of 0.6 is assumed for evaluating the coulomb stress change. Same value is assumed in subsequent figures. 

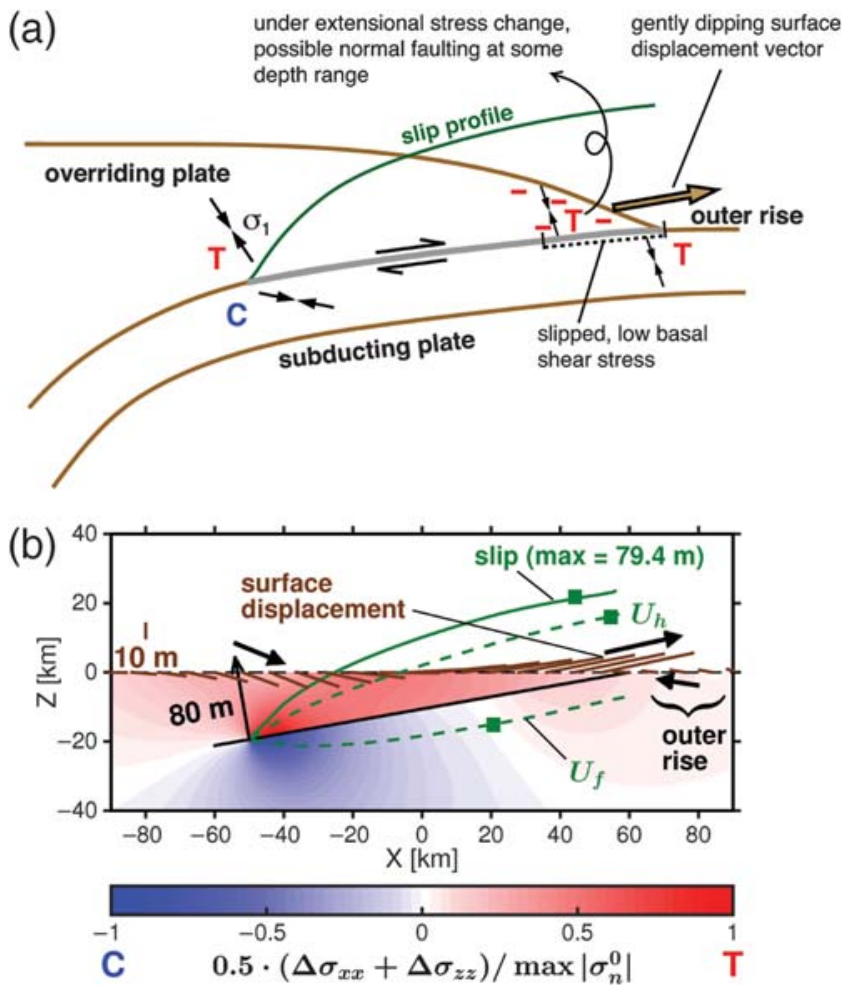

Figure 5. (a) Key deformation features induced by a surface rupture, described by a half-crack model. (b) The numerically simulated distributions of slip (solid green curve) and fault-parallel displacements (dashed green curves: $U_{h}$ for hanging wall and $U_{f}$ for footwall) on the fault (solid black line), mean stress change, and surface displacement (brown bars). The green square marks the location of maximum slip or maximum fault-parallel displacement. Thick black arrows highlight the surface displacement directions on selected portions (from right to left): seaward side and landward side of the up-dip end of the surface rupture, above the down-dip end of the surface rupture. Additional numerical results on coulomb stress change and absolute coulomb stress resolved onto various planes can be found in Figures 6 and 7, respectively.

the use of inland geodetic observations cannot rigorously distinguish between buried ruptures and surface ruptures. Supporting observational evidences of the above-predicted features include high-angle extensional fractures accompanied by normal faulting in the down-dip portion of a paleoaccretionary wedge in central European Alps (Dielforder et al., 2015), normal-type aftershocks above the down-dip end of the northern segment of the 2010 Maule earthquake (Farías et al., 2011; Yue et al., 2014), reverse-type aftershocks beneath the down-dip end of the 2011 Tohoku earthquake rupture zone (Lui et al., 2015), and systematically asymmetric aftershock patterns across the plate interface near the downdip end of the 2011 Tohoku earthquake (Chiba et al., 2012; Hasegawa et al., 2012).

Although the previous discussion pertained to the state after a megathrust rupture, important transient states during rupture propagation also deserve to be explored. Here, we focus on the overriding plate and show that during the rupture the frontal wedge may be stressed transiently with alter- nating polarities. We illustrate the idea through a surface rupture scenario with nucleation at depth (Fig. 8). Before the megathrust reaches the trench, an expanding full-crack model is applicable to describe the slip evolution (Fig. 8a). The full crack imposes a compressional stress change to the portion of the overriding plate trenchward from the up-dip rupture front, favoring reverse faulting (Figs. 8a,c and 9a,b). After the megathrust reaches the trench, large shallow slip is produced and the half-crack model becomes pertinent (Fig. 8b). The frontal wedge is then under extensional stress change, favoring normal faulting (Figs. 8b,d and 9c,d). Consistent numerical results can be found in figure 2 of Ma (2012) (e.g., before $25 \mathrm{~s}$ and after $30 \mathrm{~s}$ ) and in figure 16a of Xu, Fukuyama, et al. (2015) (e.g., before $24 \mathrm{~s}$ and after $36 \mathrm{~s}$ ), whereas here we approximately unify those numerical results by an evolving crack model from full-crack-like to half-crack-like. Effects caused by wedge-trapped waves before surface breakout, dynamic overshoot upon surface breakout, and interaction between fault interface waves and surface waves in the hanging wall after surface breakout (Brune, 1996; Shi et al., 1998; Uenishi, 2015) can also influence wedge deformation during ruptures but will require fully dynamic models for analysis. Observational evidence of failure mode reversal in the frontal wedge during a single megathrust event is still incomplete. Koge et al. (2014) found that a portion of the wedge above the large slip area of the 2011 Tohoku earthquake with a high taper angle (indicating high basal friction) hosted normal fault activity during or after the Tohoku mainshock (indicating low basal friction, also see Cubas et al., 2013). They explained this seemingly contradictory observation by a switch of the stress state in the wedge from compressionally critical to extensionally critical, due to a basal friction evolution from statically strong to dynamically weak. Alternatively, such an upper-plate deformation mode switch during megathrust rupture can be explained by our model, without necessarily assuming that the wedge is initially at a critical state. Moreover, our proposed rupture scenario, with major slip switched from at depth to near the trench, indeed has been reported by some finite-fault inversions for the 2011 Tohoku earthquake (Ide et al., 2011; Suzuki et al., 2011).

\section{Discussion}

Now we compare specific aspects of our models with those reviewed in the Introduction section. As mentioned earlier, a major limitation of the stress-drop model (Hardebeck and Hauksson, 2001) is that, being based on a fullspace consideration presumably suitable for the central part of a strike-slip fault or a deeply buried dipping fault, it only considers the effect of deviatoric stress changes while it ignores the volumetric component. Therefore, it predicts a similar aftershock pattern in the upper and lower plates, which is in contrast to the observed asymmetric aftershock pattern near the downdip end of the 2011 Tohoku mainshock (Chiba et al., 2012; Hasegawa et al., 2012). Such asymmetric aftershock pattern reflects contributions from antisymmetric volumetric deforma- 

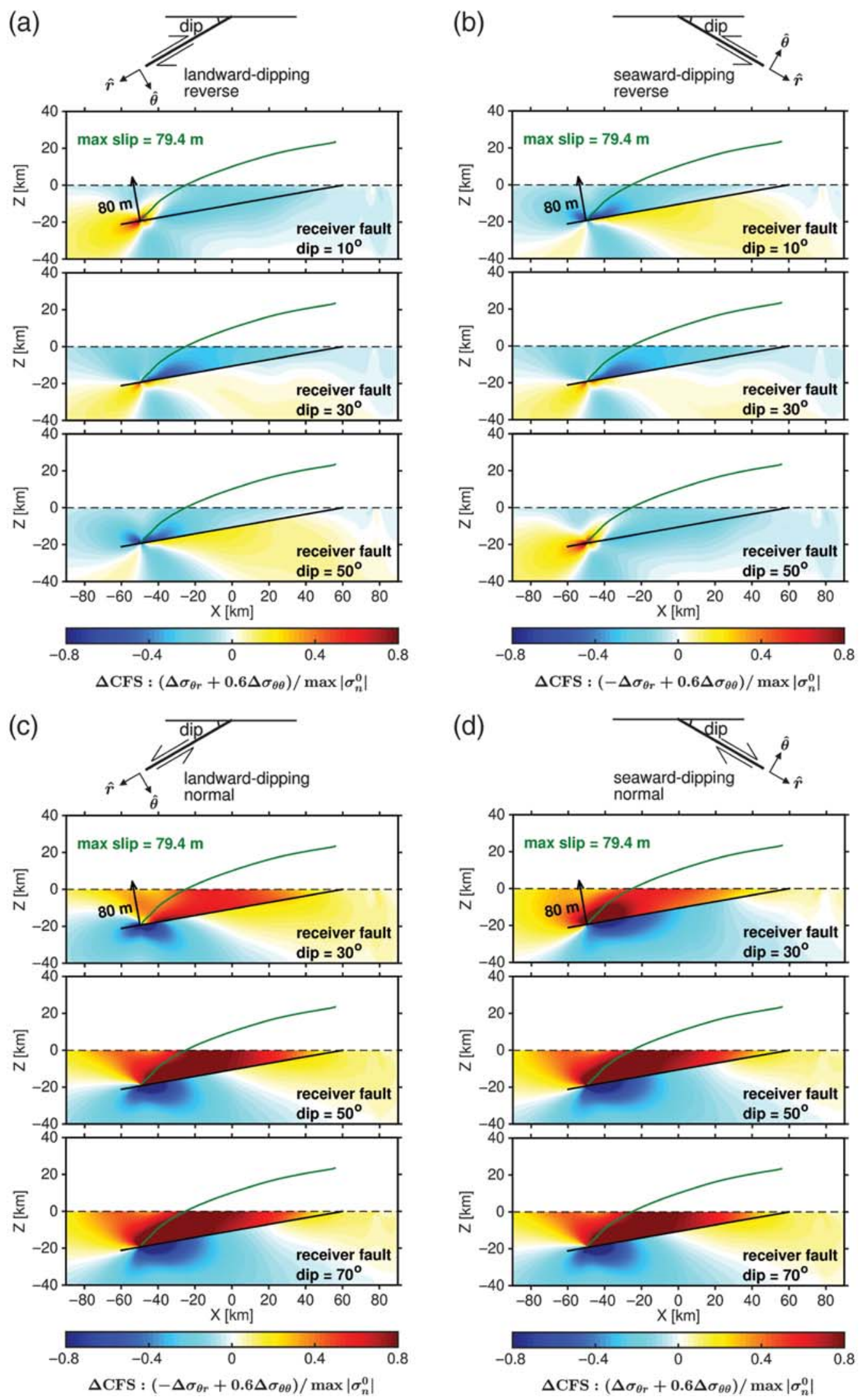

Figure 6. Distribution of normalized $\triangle$ CFS resolved onto several (a,c) landward-dipping and (b,d) seaward-dipping planes, following a surface rupture as illustrated in Figure 5. Sign of shear stress is chosen to favor reverse faulting in (a) and (b), and normal faulting in (c) and (d). Green curves show the slip distribution along the fault. 
(a)
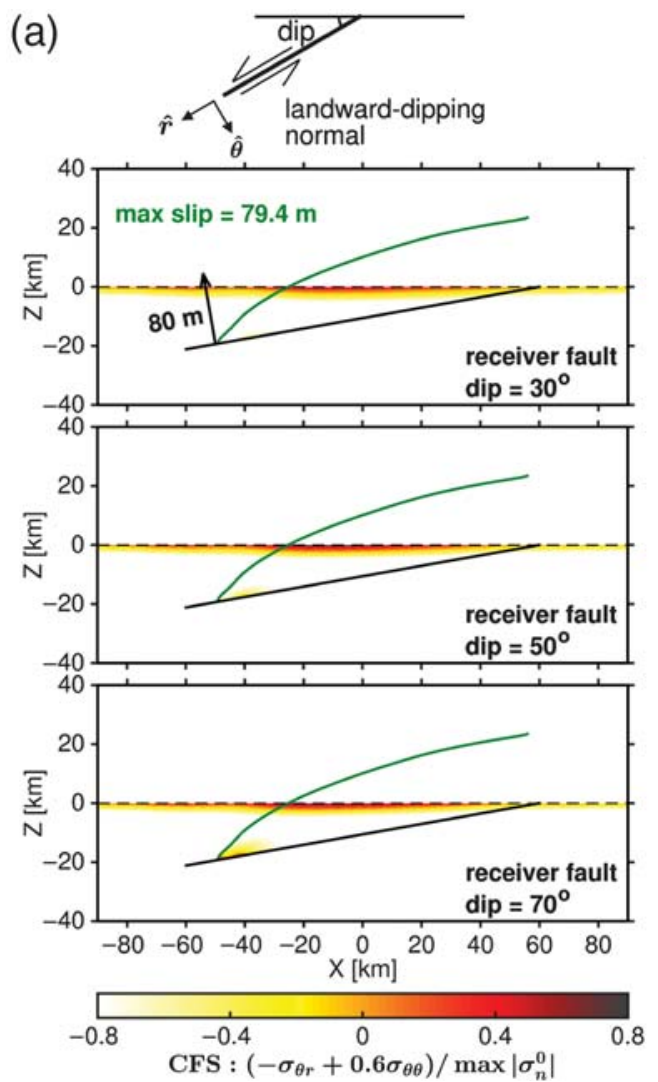

(b)
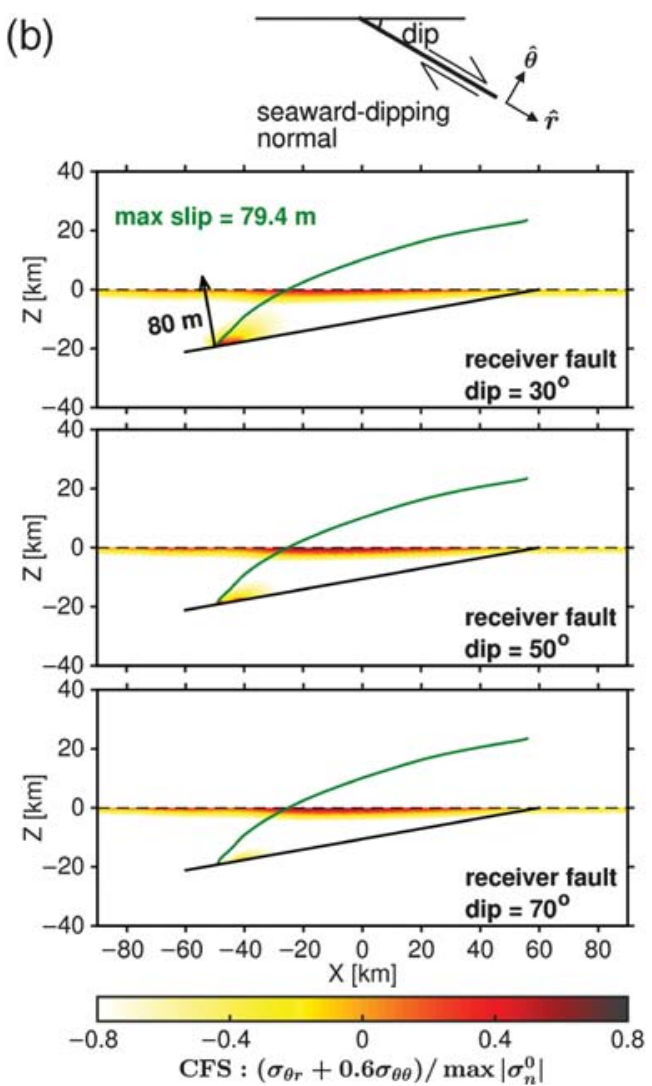

Figure 7. Distribution of normalized CFS resolved onto several (a) landward-dipping and (b) seaward-dipping planes, following a surface rupture as illustrated in Figure 5. CFS is calculated based on the total stresses, which are the sum of initial ones (Fig. 2) and perturbed ones. Sign of shear stress is chosen to favor normal faulting in both (a) and (b). Green curves show the slip distribution along the fault. Even with the initial maximum compressive stress $\sigma_{1}^{0}$ dipping at $10^{\circ}$ to the plate interface, normal faulting may still be triggered in the overriding plate following surface rupture. One cluster is located near the down-dip end, and the other is widely distributed at some shallow depth. The former can be well understood by the strong fault rotation and fault-parallel extension near the crack tip region (Figs. $1 \mathrm{~b}$ and $5 \mathrm{~b}$ ), whereas the latter stems from the fact that effects caused by fault rotation and fault-parallel extension, though becoming weakened away from the crack tip, can still reverse the state set by the low-magnitude initial compressive stress near the surface.

tion, which can be well understood from the rotation of the fault plane and the gradient of fault-parallel displacement based on the crack models (Fig. 1). Also because of the contribution from volumetric deformation to stress rotation (Fig. 1), an initial high stressing angle $\left(>45^{\circ}\right)$, as required by the stress-drop model, is no longer needed to explain triggered normal faulting following a megathrust rupture, at least for regions where the rupture-induced deformation dominates (Fig. 7). Our study, along with previous ones (e.g., Lin and Stein, 2004; Davis et al., 2015), suggests ways in which observational studies of aftershock patterns could be improved by carefully considering when the volumetric deformation or the free-surface effect becomes important. Instead of grouping all aftershocks together, one could distinguish aftershocks triggered primarily by deviatoric deformation, by volumetric deformation, and by a combination of the two. One could also distinguish buried megathrust ruptures (or buried segments of the rupture) from those reaching the trench. Following these points, a critical question needs to be investigated by future studies: how significantly the inference of mainshock stress drop based on nearby intraplate aftershocks can be biased by ignoring the mainshock-induced volumetric deformation, especially when the latter spans over a spatial scale comparable to the source dimension (e.g., in the overriding plate after a surface rupture as in Fig. 5) or locally shows a persistent sign on both sides of the fault (e.g., near the up-dip end of a surface rupture as in Fig. 5b).

Another comparison is made with the dynamic critical taper model developed by Wang and $\mathrm{Hu}$ (2006), focusing on megathrust behavior toward the up-dip direction. As mentioned earlier, a significant limitation of this model is that it relies on the steady-state basal friction to describe the stress state within the overriding plate, during each phase of seismic cycles. Once the phase and the focused subduction zone segment are selected, it still treats the wedge as being under quasi-static equilibrium. Specifically, it predicts that during the coseismic phase the overriding plate above the seismogenic zone stays in stable or extensional failure regime, as a result of reduction in basal friction. However, as implied by our study (Fig. 8a,c), transient compressional failure may be triggered in the overriding plate during the up-dip propagation of the megathrust rupture, which is associated with a 
(a)

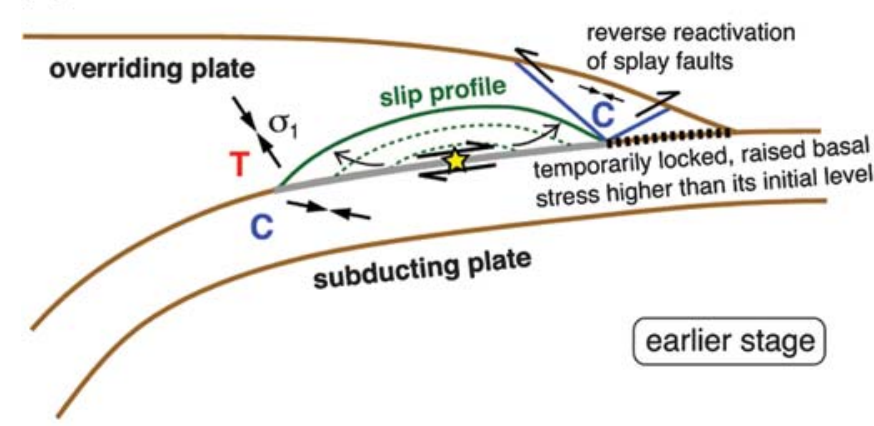

(c)

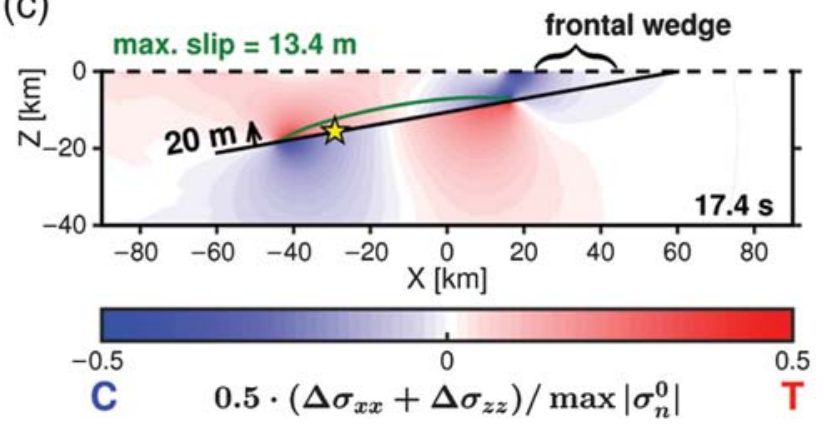

(b)

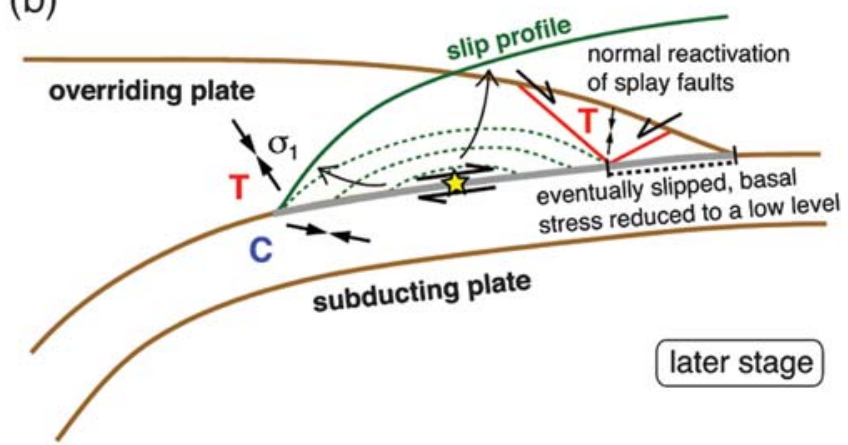

(d)

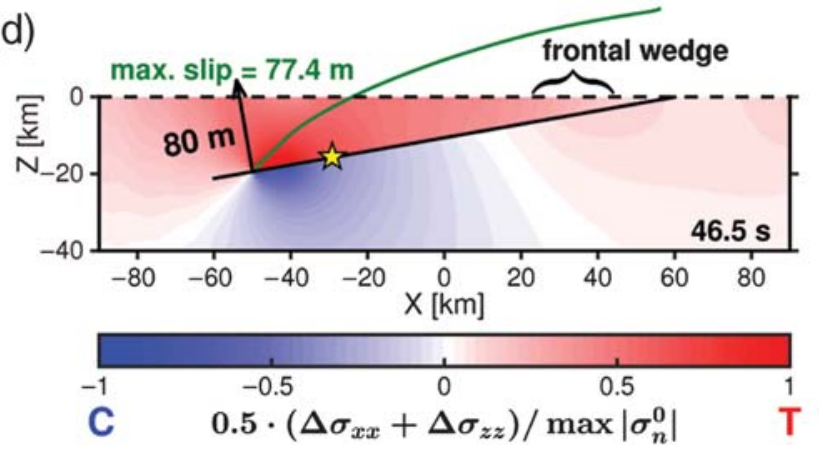

Figure 8. Key deformation features induced by a deeply nucleated rupture, (a) before and (b) after it reaches the surface. (c) and (d) The numerically simulated slip distribution (green curve) on the fault (solid black line) and mean stress change during each stage for (a) and (b), respectively. Yellow star shows the rupture initiation location. Additional numerical results on coulomb stress change resolved onto a landward- or seaward-dipping plane at $30^{\circ}$ can be found in Figure 9.

transient basal strengthening around the rupture front before entering the weakening stage (Xu, Fukuyama et al., 2015). Such a compressional feature can be greatly enhanced as the rupture front approaches the trench, because the ruptureinduced stress change generally scales with the rupture zone dimension (Fig. 9a,b), free-surface effects become more prominent, and triggered failure around the rupture front has more opportunity to reach the surface (Rosenau and Oncken, 2009; Ma, 2012). These transient features arising in dynamic rupture models are not present in the dynamic critical taper model (which is actually a quasi-static model).

From the above comparison, we see how our study fills a gap in the dynamic critical taper model in which transient effect during rupture propagation was ignored. The rupture evolution from full-crack-like to half-crack-like (Fig. 8) leads to early compressional failure overprinted by later extensional failure during a single megathrust event, which might be the case for the frontal wedge during the 2011 Tohoku earthquake (Koge et al., 2014). A similar scenario may have also occurred in the Nankai Trough, based on a similar current stress state in the frontal wedge between the Nankai Trough and the Japan Trench (Lin et al., 2015). If our proposed scenario is characteristic in a sense that it repeatedly occurs in a region, then the geometry and the internal faulting structure of the frontal wedge must be mainly shaped during megathrust earthquakes in that region. A challenging task for future work is to systematically examine the response of the wedge to an effective basal resistance described as statically strong (or even stronger at low slip rate) but dynamically weak (or much weaker at high slip rate), due to intrinsic frictional behavior (Rice, 1996; Faulkner et al., 2011) or to opposite normal stress changes ahead of and behind the rupture front induced by free surface (Oglesby et al., 1998) and/or bimaterial effects (Andrews and Ben-Zion, 1997; Ma and Beroza, 2008; Xu, Ben-Zion, et al., 2015; Shlomai and Fineberg, 2016). Of particular interest is a possibility of fault opening or total separation of the hanging wall from the footwall near the toe during megathrust earthquakes (Brune, 1996; Shi et al., 1998). It should be emphasized that a statically strong fault can still fail at averagely low background shear stress (thus appearing to be weak macroscopically), as failure can initiate and propagate by localized stress concentrator (Tullis, 2007; Kato, 2012). Some outstanding questions then can be addressed regarding the influence of inhomogeneity, such as which level of basal stress and strength (initial, peak, residual, or an average over space and time) can be inferred from the properties of the wedge, if the wedge (or part of it) stays stable under averagely low basal stress during the interseismic phase but experiences transient compressional failure under rupture-tip basal strengthening during the coseismic phase, if the wedge frequently experiences a switching between compressional and extensional stress regimes over earthquake cycles, and if the entire wedge is not at critical state (e.g., only near the surface or at some depth). 
(a)
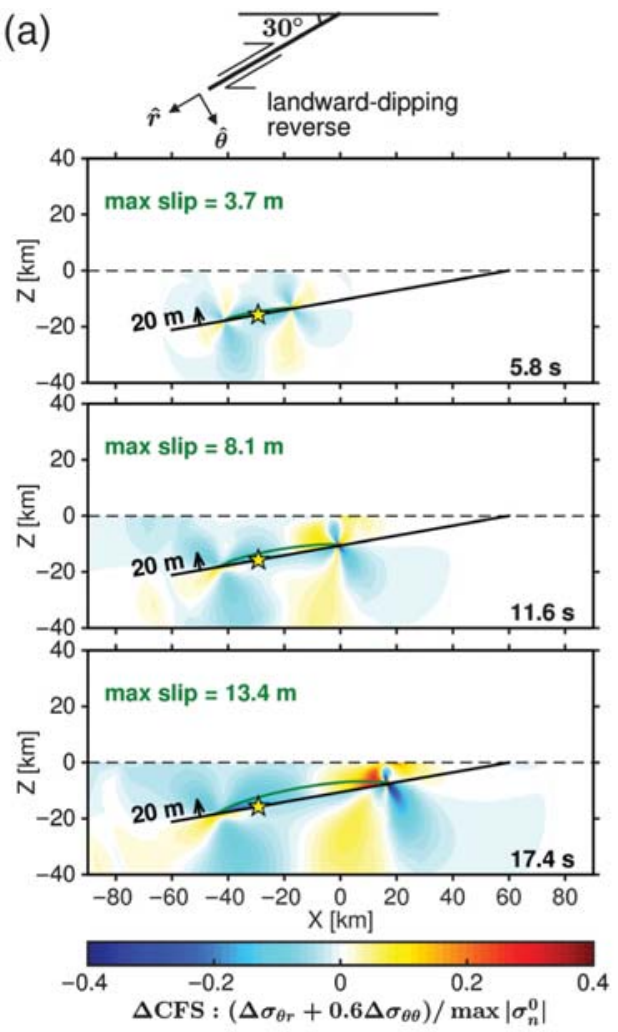

(c)
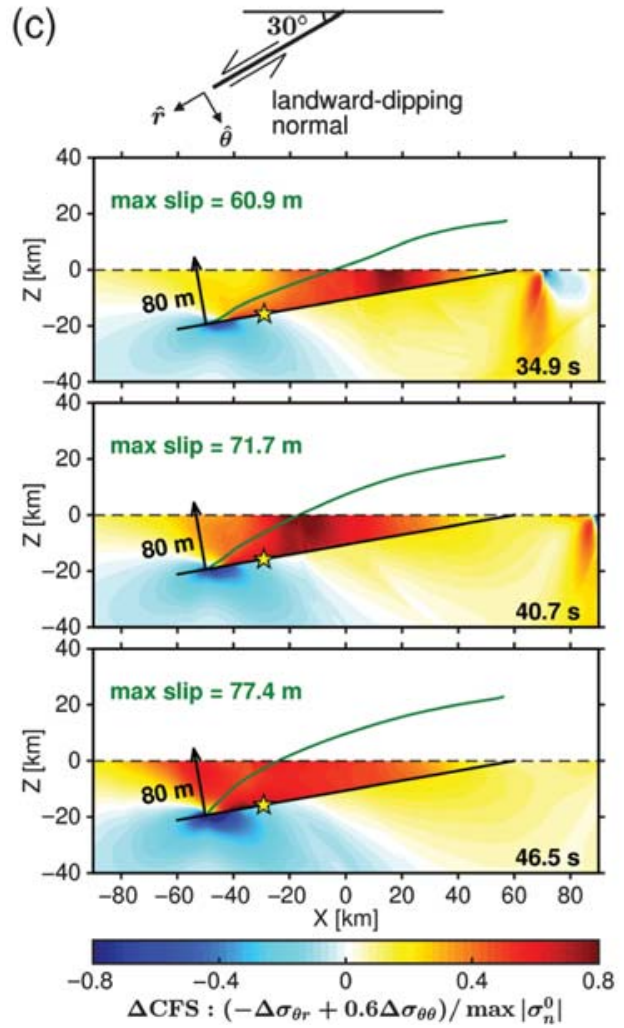

(b)
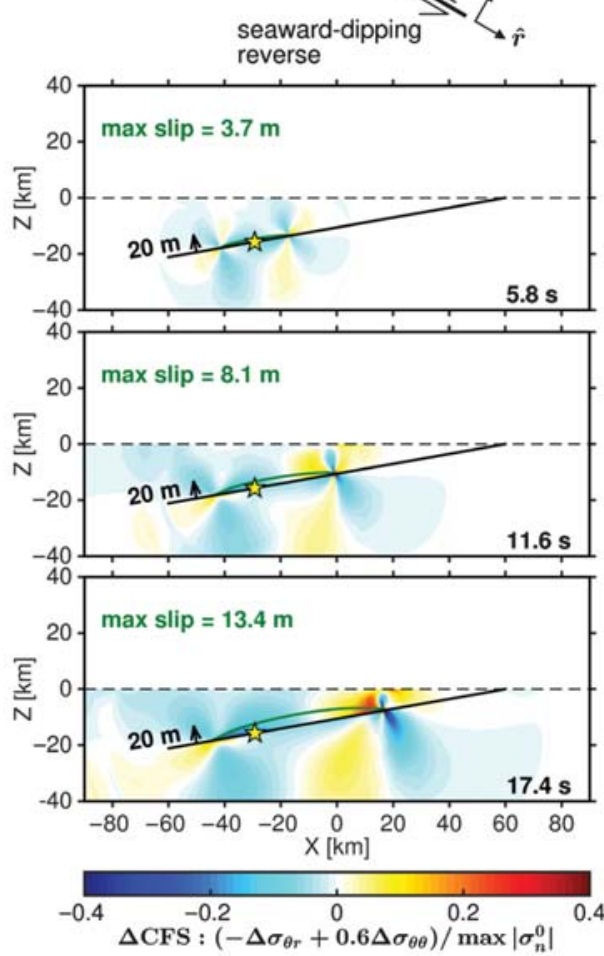

(d)
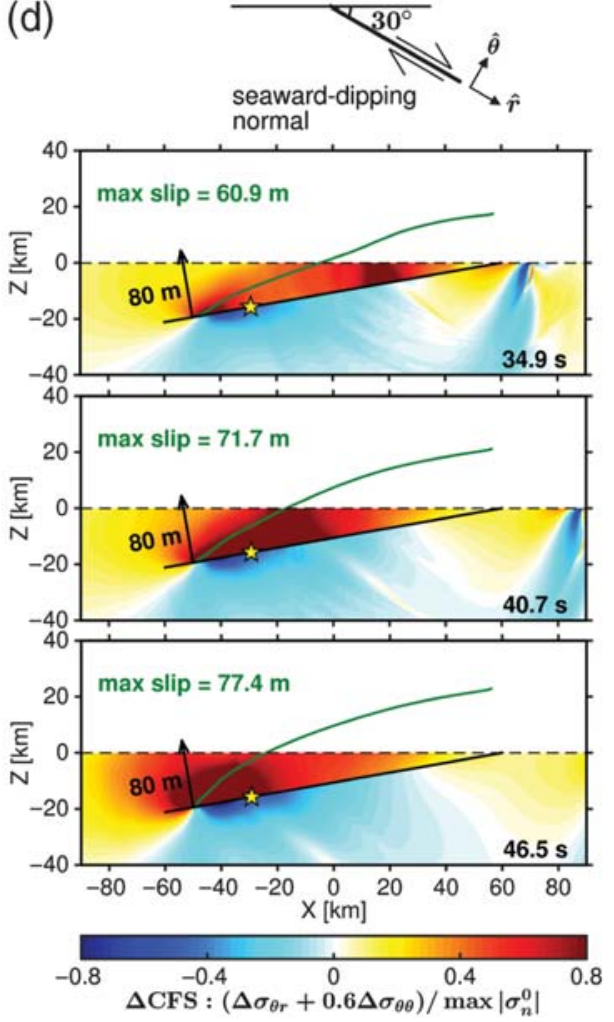

Figure 9. Distribution of normalized $\triangle \mathrm{CFS}$ resolved onto (a,c) landward-dipping $30^{\circ}$ and (b,d) seaward-dipping $30^{\circ}$ planes, during two stages of a deeply nucleated rupture $(a, b)$ before and $(c, d)$ after it reaches the surface. Sign of shear stress is chosen to favor reverse faulting at the early stage in (a) and (b) and normal faulting at the later stage in (c) and (d). Yellow stars show the hypocenters of the rupture (in a fixed position), and green curves show the (evolving) slip distribution along the fault. Note that before the rupture, the frontal wedge is not at a critical state according to the assumed internal-friction coefficient of 0.6 and the initial stress field in Figure 2, whereas during the rupture it may experience a transition from compressional failure to extensional failure. 
In this study, certain features of surface ruptures have been explained by referring to well-known results of buried ruptures. We found that this analogy-based simple approach worked quite well, as validated by numerical simulations and by many observational examples. The reason for this success may be attributed to the unique solution of the studied boundary value problems: as long as the regional properties (e.g., variation in the displacement vector) are similar, so will be the nearby-induced deformations. Based on this idea, familiar results caused by different mechanisms can be connected. For example, the similar kinematics marked by a changing direction in displacement vector, seen near the extensional end(s) of a rupture zone (Fig. 1a,b), in the limit analysis model with a decreasing effective basal friction toward the trench (Cubas et al., 2013), in the bending slab near the trench (Lay, 2015), or along the trailing edge of a subducting seamount (Ding and Lin, 2012), explains the common occurrence of triggered normal faulting in the nearby regions. A discussion on triggered reverse faulting near geometric or strength irregularities along the megathrust can be found in Xu, Fukuyama, et al. (2015). Putting these encouraging implications together, it may promote in the future the development of effective fault models that can handle a variety of equivalent mechanisms in a unified framework. Then the universal physics behind various mechanisms can be recognized, which will greatly broaden and deepen our understanding of megathrust earthquakes. As discussed above, we see how our study goes beyond the traditional applications of the coulomb stress change model, because we also provide comparative views.

The crack models and the numerical simulations in this study also have limitations. We have ignored the influence of seafloor topography, possible velocity contrast across the fault, 3D effects such as along-strike variation of slip, smallscale effects caused by local heterogeneities, varying dip of the plate interface along depth, effects caused by pore fluid, relaxation of a viscoelastic asthenosphere, and many other processes. These factors can be examined by detailed modeling work to achieve a more complete understanding of plate deformation following megathrust earthquakes.

\section{Conclusions}

Inspired by the well-known features around mode II shear cracks, we show that simple crack models are applicable at plate scale to understand deformation induced by megathrust earthquakes. We classify megathrust earthquakes as buried ruptures represented by a full-crack model, and as surface ruptures represented by a half-crack model. We apply an analogy-based approach to interpret the half-crack model by referring to well-known results of the full-crack model, whose validity has been later confirmed by numerical simulations. Full-crack and half-crack models explain well the contrasting faulting styles in the shallow part of the overriding plate: dominated by reverse faulting associated with buried ruptures and by normal faulting with surface ruptures.
The difference in proximity to the trench between the two crack models explains the triggered outer-rise normal faulting often seen with surface ruptures. Both crack models predict similar results near the down-dip end, which also explains the observed asymmetric aftershock pattern in that region, with preferred normal aftershocks and steep $\sigma_{1}$ direction in the overriding plate and reverse aftershocks and shallow $\sigma_{1}$ direction in the subducting plate. We also introduce an evolving crack model, from full crack to half crack, which provides the foundation for understanding the coexistence of compressional and extensional features in the frontal wedge during surface megathrust ruptures. Our study provides a simple tool with transferable knowledge to understand the big picture of aftershock patterns following megathrust earthquakes and to constrain slip models with deformation observations. Future work can be done to investigate such connections more quantitatively.

\section{Data and Resources}

The numerical simulations in this article were conducted at the National Research Institute for Earth Science and Disaster Resilience (NIED). The spectral element code SEM2DPACK is available at http://sourceforge.net/projects/sem2d (last accessed September 2015). Other data can be found from the cited resources listed in the references.

\section{Acknowledgments}

S. Xu thanks Takanori Matsuzawa, Ryo Okuwaki, Tatsuhiko Saito, Kaoru Sawazaki, Yuji Yagi, and Keisuke Yoshida for providing comments on an earlier version of the work. We thank Raúl Madariaga for sending us his computational results for comparison. We thank Raúl Madariaga, an anonymous reviewer, and Associate Editor Cezar I. Trifu for their constructive comments. This work was funded by the National Research Institute for Earth Science and Disaster Resilience (NIED) under project "Development of the Earthquake Activity Monitoring and Forecasting" and by the Ministry of Education, Culture, Sports, Science and Technology of Japan (MEXT) under project "Wide-area Earthquake Disaster Prevention Research along the Nankai Trough."

\section{References}

Ampuero, J.-P. (2002). Etude physique et numérique de la nucléation des séismes, Ph.D. Thesis, Université Paris 7, Denis Diderot, Paris, France (in French).

Anders, M. H., S. E. Laubach, and C. H. Scholz (2014). Microfractures: A review, J. Struct. Geol. 69, 377-394, doi: 10.1016/j.jsg.2014.05.011.

Ando, R., and K. Imanishi (2011). Possibility of $M_{\mathrm{w}} 9.0$ mainshock triggered by diffusional propagation of after-slip from $M_{\mathrm{w}} 7.3$ foreshock, Earth Planets Space 63, no. 7, 767-771, doi: 10.5047/eps.2011.05.016.

Andrews, D. J., and Y. Ben-Zion (1997). Wrinkle-like slip pulse on a fault between different materials, J. Geophys. Res. 102, no. B1, 553-571, doi: 10.1029/96JB02856.

Blenkinsop, T. G. (2008). Relationships between faults, extension fractures and veins, and stress, J. Struct. Geol. 30, no. 5, 622-632, doi: 10.1016/ j.jsg.2008.01.008.

Brown, L., K. Wang, and T. Sun (2015). Static stress drop in the $M_{\mathrm{w}} 9$ Tohoku-oki earthquake: Heterogeneous distribution and low average value, Geophys. Res. Lett. 42, no. 24, 10,595-10,600, doi: 10.1002/ 2015GL066361. 
Brune, J. N. (1996). Particle motion in a physical model of shallow angle thrust faulting, Proc. Indian Acad. Sci. 105, 197-206.

Chiba, K., Y. Iio, and Y. Fukahata (2012). Detailed stress fields in the focal region of the 2011 off the Pacific coast of Tohoku earthquake-Implication for the distribution of moment release, Earth Planets Space 64, no. 12, 1157-1165, doi: 10.5047/eps.2012.07.008.

Cortés-Aranda, J., G. González, D. Rémy, and J. Martinod (2015). Normal upper plate fault reactivation in northern Chile and the subduction earthquake cycle: From geological observations and static Coulomb Failure Stress (CFS) change, Tectonophysics 639, 118-131, doi: 10.1016/j.tecto.2014.11.019.

Cubas, N., J.-P. Avouac, Y. M. Leroy, and A. Pons (2013). Low friction along the high slip patch of the $2011 M_{\mathrm{w}} 9.0$ Tohoku-Oki earthquake required from the wedge structure and extensional splay faults, Geophys. Res. Lett. 40, no. 16, 4231-4237, doi: 10.1002/grl.50682.

Davis, E. E., H. Villinger, and T. Sun (2015). Slow and delayed deformation and uplift of the outermost subduction prism following ETS and seismogenic slip events beneath Nicoya Peninsula, Costa Rica, Earth Planet. Sci. Lett. 410, 117-127, doi: 10.1016/j.epsl.2014.11.015.

Dielforder, A., H. Vollstaedt, T. Vennemann, A. Berger, and M. Herwegh (2015). Linking megathrust earthquakes to brittle deformation in a fossil accretionary complex, Nat. Comm. 6, Article Number 7504, doi: $10.1038 /$ ncomms 8504 .

Ding, M., and J. Lin (2012). Effects of a subducting seamount on the overriding plate deformation and faulting, AGU (Fall Meet.), Abstract T11A-2530

Farías, M., D. Comte, S. Roecker, D. Carrizo, and M. Pardo (2011). Crustal extensional faulting triggered by the 2010 Chilean earthquake: The Pichilemu seismic sequence, Tectonics 30, no. 6, TC6010, doi: 10.1029/ 2011 TC002888.

Faulkner, D. R., T. M. Mitchell, J. Behnsen, T. Hirose, and T. Shimamoto (2011). Stuck in the mud? Earthquake nucleation and propagation through accretionary forearcs, Geophys. Res. Lett. 38, no. 18, L18303, doi: 10.1029/2011GL048552.

Gardi, A., A. Lemoine, R. Madariaga, and J. Campos (2006). Modeling of stress transfer in the Coquimbo region of central Chile, J. Geophys. Res. 111, no. B04307, doi: 10.1029/2004JB003440.

Geist, E. L., and R. Dmowska (1999). Local tsunamis and distributed slip at the source, Pure Appl. Geophys. 154, no. 3, 485-512, doi: 10.1007/ s000240050241.

Hardebeck, J. L. (2012). Coseismic and postseismic stress rotations due to great subduction zone earthquakes, Geophys. Res. Lett. 39, no. 21, L21313, doi: 10.1029/2012GL053438.

Hardebeck, J. L. (2015). Stress orientations in subduction zones and the strength of subduction megathrust faults, Science 349, no. 6253, 1213-1216, doi: 10.1126/science.aac5625.

Hardebeck, J. L., and E. Hauksson (2001). Crustal stress field in southern California and its implications for fault mechanics, J. Geophys. Res. 106, no. B10, 21,859-21,882, doi: 10.1029/2001JB000292.

Hasegawa, A., K. Yoshida, Y. Asano, T. Okada, T. Iinuma, and Y. Ito (2012). Change in stress field after the 2011 Great Tohoku-Oki earthquake, Earth Planet. Sci. Lett. 355-356, 231-243, doi: 10.1016/j.eps1.2012.08.042.

Hasegawa, A., K. Yoshida, and T. Okada (2011). Nearly complete stress drop in the $2011 M_{\mathrm{w}} 9.0$ off the Pacific coast of Tohoku earthquake, Earth Planets Space 63, no. 7, 703-707, doi: 10.5047/eps.2011.06.007.

Hicks, S. P., A. Rietbrock, I. M. A. Ryder, C.-S. Lee, and M. Miller (2014). Anatomy of a megathrust: The 2010 M 8.8 Maule, Chile earthquake rupture zone imaged using seismic tomography, Earth Planet. Sci. Lett. 405, 142-155, doi: 10.1016/j.eps1.2014.08.028.

Huang, Y., J.-P. Ampuero, and H. Kanamori (2014). Slip-weakening models of the 2011 Tohoku-Oki earthquake and constraints on stress drop and fracture energy, Pure Appl. Geophys. 171, no. 10, 2555-2568, doi: 10.1007/s00024-013-0718-2.

Huang, Y., L. Meng, and J.-P. Ampuero (2012). A dynamic model of the frequency-dependent rupture process of the 2011 Tohoku-Oki earthquake, Earth Planets Space 64, no. 12, 1061-1066, doi: 10.5047/ eps.2012.05.011.
Ide, S., A. Baltay, and G. C. Beroza (2011). Shallow dynamic overshoot and energetic deep rupture in the $2011 M_{\mathrm{w}} 9.0$ Tohoku-Oki earthquake, Science 332, 1426-1429, doi: 10.1126/science.1207020.

Imanishi, K., R. Ando, and Y. Kuwahara (2012). Unusual shallow normalfaulting earthquake sequence in compressional northeast Japan activated after the 2011 off the Pacific coast of Tohoku earthquake, Geophys. Res. Lett. 39, L09306, doi: 10.1029/2012GL051491.

Ito, Y., T. Tsuji, Y. Osada, M. Kido, D. Inazu, Y. Hayashi, H. Tsushima, R. Hino, and H. Fujimoto (2011). Frontal wedge deformation near the source region of the 2011 Tohoku-Oki earthquake. Geophys. Res. Lett. 38, L00G05, doi: 10.1029/2011GL048355.

Kato, N. (2012). Fracture energies at the rupture nucleation points of large interplate earthquakes, Earth Planet. Sci. Lett. 353-354, 190-197, doi: 10.1016/j.eps1.2012.08.015.

Kim, Y.-S., D. C. P. Peacock, and D. J. Sanderson (2004). Fault damage zones, J. Struct. Geol. 26, no. 3, 503-517, doi: 10.1016/j.jsg.2003.08.002.

King, G. C. P., R. S. Stein, and J. Lin (1994). Static stress changes and the triggering of earthquakes, Bull. Seismol. Soc. Am. 84, no. 3, 935-953.

Koge, H., T. Fujiwara, S. Kodaira, T. Sasaki, J. Kameda, Y. Kitamura, M. Hamahashi, R. Fukuchi, A. Yamaguchi, Y. Hamada, et al. (2014). Friction properties of the plate boundary megathrust beneath the frontal wedge near the Japan Trench: An inference from topographic variation, Earth Planets Space 66, no. 1, 1-10, doi: 10.1186/s40623014-0153-3.

Kozdon, J. E., and E. M. Dunham (2013). Rupture to the trench: Dynamic rupture simulations of the 11 March 2011 Tohoku earthquake, Bull. Seismol. Soc. Am. 103, no. 2B, 1275-1289, doi: 10.1785/ 0120120136.

Lay, T. (2015). The surge of great earthquakes from 2004 to 2014, Earth Planet. Sci. Lett. 409, 133-146, doi: 10.1016/j.epsl.2014.10.047.

Lay, T., H. Kanamori, C. J. Ammon, K. D. Koper, A. R. Hutko, L. Ye, H. Yue, and T. M. Rushing (2012). Depth-varying rupture properties of subduction zone megathrust faults, J. Geophys. Res. 117, no. B4, B04311, doi: 10.1029/2011JB009133.

Li, S., M. Moreno, M. Rosenau, D. Melnick, and O. Oncken (2014). Splay fault triggering by great subduction earthquakes inferred from finite element models, Geophys. Res. Lett. 41, no. 2, 385-391, doi: 10.1002/2013GL058598.

Lin, J., and R. S. Stein (2004). Stress triggering in thrust and subduction earthquakes and stress interaction between the southern San Andreas and nearby thrust and strike-slip faults, J. Geophys. Res. 109, no. B02303, doi: 10.1029/2003JB002607.

Lin, W., T. B. Byrne, M. Kinoshita, L. C. McNeill, C. Chang, J. C. Lewis, Y. Yamamoto, D. M. Saffer, J. C. Moore, H. Y. Wu, et al. (2015). Distribution of stress state in the Nankai subduction zone, southwest Japan and a comparison with Japan Trench, Tectonophysics, in press, doi: 10.1016/j.tecto.2015.05.008.

Lui, S. K., D. Helmberger, S. Wei, Y. Huang, and R. W. Graves (2015). Interrogation of the megathrust zone in the Tohoku-Oki seismic region by waveform complexity: Intraslab earthquake rupture and reactivation of subducted normal faults, Pure Appl. Geophys. 172, no. 12, 34253437, doi: 10.1007/s00024-015-1042-9.

Ma, S. (2012). A self-consistent mechanism for slow dynamic deformation and tsunami generation for earthquakes in the shallow subduction zone, Geophys. Res. Lett. 39, no. 11, L11310, doi: 10.1029/2012GL051854.

Ma, S., and G. C. Beroza (2008). Rupture dynamics on a bimaterial interface for dipping faults, Bull. Seismol. Soc. Am. 98, no. 4, 1642-1658, doi: 10.1785/0120070201.

McLaskey, G. C., B. D. Kilgore, and N. M. Beeler (2015). Slip-pulse rupture behavior on a 2 m granite fault, Geophys. Res. Lett. 42, no. 17, 70397045, doi: 10.1002/2015GL065207.

Melnick, D., M. Moreno, M. Motagh, M. Cisternas, and R. L. Wesson (2012). Splay fault slip during the $M_{\mathrm{w}} 8.82010$ Maule Chile earthquake, Geology 40, no. 3, 251-254, doi: 10.1130/G32712.1.

Meng, L., A. Inbal, and J.-P. Ampuero (2011). A window into the complexity of the dynamic rupture of the $2011 M_{\mathrm{w}} 9$ Tohoku-Oki earthquake, Geophys. Res. Lett. 38, L00G07, doi: 10.1029/2011GL048118. 
Misra, S., N. Mandal, R. Dhar, and C. Chakraborty (2009). Mechanisms of deformation localization at the tips of shear fractures: Findings from analogue experiments and field evidence, J. Geophys. Res. 114, no. B4, B04204, doi: 10.1029/2008JB005737.

Moreno, M., D. Melnick, M. Rosenau, J. Baez, J. Klotz, O. Oncken, A. Tassara, J. Chen, K. Bataille, M. Bevis, et al. (2012). Toward understanding tectonic control on the $M_{\mathrm{w}} 8.82010$ Maule Chile earthquake, Earth Planet. Sci. Lett. 321-322, 152-165, doi: 10.1016/j.eps1.2012.01.006.

Obana, K., S. Kodaira, M. Shinohara, R. Hino, K. Uehira, H. Shiobara, K. Nakahigashi, T. Yamada, H. Sugioka, A. Ito, et al. (2013). Aftershocks near the updip end of the 2011 Tohoku-Oki earthquake, Earth Planet. Sci. Lett. 382, 111-116, doi: 10.1016/j.eps1.2013.09.007.

Oglesby, D. D., R. J. Archuleta, and S. B. Nielsen (1998). Earthquakes on dipping faults: The effects of broken symmetry, Science 280, no. 5366, 1055-1059, doi: 10.1126/science.280.5366.1055.

Okada, Y. (2003). Paradox on vertical displacement due to a fault model, $J$. Geod. Soc. Jpn. 49, no. 2, 99-119, doi: 10.11366/sokuchi1954.49.99.

Pollard, D. D., and P. Segall (1987). Theoretical displacements and stresses near fractures in rock: With applications to faults, joints, veins, dikes, and solution surfaces, in Fracture Mechanics of Rock, B. K. Atkinson (Editor), Academic Press, London, United Kingdom, 277-349.

Rice, J. R. (1996). Low-stress faulting: Strong but brittle faults with local stress concentrations, Eos Trans. AGU 77, no. 46 (Fall Meet. Suppl.), Abstract F471.

Rosenau, M., and O. Oncken (2009). Fore-arc deformation controls frequency-size distribution of megathrust earthquakes in subduction zones, J. Geophys. Res. 114, no. B10, B10311, doi: 10.1029/2009JB006359.

Rudnicki, J. W., and M. Wu (1995). Mechanics of dip-slip faulting in an elastic half-space, J. Geophys. Res. 100, no. B11, 22,173-22,186, doi: 10.1029/ 95JB02246.

Satake, K., and Y. Tanioka (1999). Sources of tsunami and tsunamigenic earthquakes in subduction zones, Pure Appl. Geophys. 154, 467-483, doi: 10.1007/978-3-0348-8679-6_5.

Shi, B., A. Anooshehpoor, J. N. Brune, and Y. Zeng (1998). Dynamics of thrust faulting: 2D lattice model, Bull. Seismol. Soc. Am. 88, no. 6, 1484-1494.

Shlomai, H., and J. Fineberg (2016). The structure of slip-pulses and supershear ruptures driving slip in bimaterial friction, Nat. Comm. 7, 11787, doi: $10.1038 /$ ncomms 11787 .

Sun, T., and K. Wang (2015). Viscoelastic relaxation following subduction earthquakes and its effects on afterslip determination, J. Geophys. Res. 120, no. 2, 1329-1344, doi: 10.1002/2014JB011707.

Suzuki, W., S. Aoi, H. Sekiguchi, and T. Kunugi (2011). Rupture process of the 2011 Tohoku-Oki mega-thrust earthquake (M 9.0) inverted from strong motion data, Geophys. Res. Lett. 38, L00G16, doi: 10.1029/ 2011GL049136.

Tajima, F., J. Mori, and B. Kennett (2013). A review of the 2011 Tohoku-Oki earthquake $\left(M_{\mathrm{w}}\right.$ 9.0): Large-scale rupture across heterogeneous plate coupling, Tectonophysics 586, 15-34, doi: 10.1016/j.tecto.2012.09.014.
Tullis, T. E. (2007). Friction of rock at earthquake slip rates, in Treatise on Geophysics, H. Kanamori (Editor), Vol. 4, Elsevier, Amsterdam, The Netherlands, 131-152.

Uenishi, K. (2015). Dynamic dip-slip fault rupture in a layered geological medium: Broken symmetry of seismic motion, Eng. Fail. Anal. 58, 380-393, doi: 10.1016/j.engfailanal.2015.07.004.

Wang, K., and Y. Hu (2006). Accretionary prisms in subduction earthquake cycles: The theory of dynamic Coulomb wedge, J. Geophys. Res. 111, no. B6, B06410, doi: 10.1029/2005JB004094.

$\mathrm{Xu}, \mathrm{S}$., and Y. Ben-Zion (2013). Numerical and theoretical analyses of inplane dynamic rupture on a frictional interface and off-fault yielding patterns at different scales, Geophys. J. Int. 193, no. 1, 304-320, doi: 10.1093/gji/ggs 105 .

Xu, S., Y. Ben-Zion, J.-P. Ampuero, and V. Lyakhovsky (2015). Dynamic ruptures on a frictional interface with off-fault brittle damage: Feedback mechanisms and effects on slip and near-fault motion, Pure Appl. Geophys. 172, no. 5, 1243-1267, doi: 10.1007/s00024-014-0923-7.

Xu, S., E. Fukuyama, Y. Ben-Zion, and J.-P. Ampuero (2015). Dynamic rupture activation of backthrust fault branching, Tectonophysics 644-645, 161-183, doi: 10.1016/j.tecto.2015.01.011.

Yang, Y.-R., K. M. Johnson, and R. Y. Chuang (2013). Inversion for absolute deviatoric crustal stress using focal mechanisms and coseismic stress changes: The 2011 M 9 Tohoku-oki, Japan, earthquake, J. Geophys. Res. 118, no. 10, 5516-5529, doi: 10.1002/jgrb.50389.

Yue, H., T. Lay, L. Rivera, C. An, C. Vigny, X. Tong, and J. C. Báez Soto (2014). Localized fault slip to the trench in the 2010 Maule, Chile $M_{\mathrm{w}}=8.8$ earthquake from joint inversion of high-rate GPS, teleseismic body waves, InSAR, campaign GPS, and tsunami observations, $J$. Geophys. Res. 119, no. 10, 7786-7804, doi: 10.1002/2014JB011340.

National Research Institute for Earth Science and Disaster Resilience 3-1 Tennodai

Tsukuba, Ibaraki 305-0006, Japan

shiqing@bosai.go.jp

fuku@bosai.go.jp

(S.X., E.F.)

California Institute of Technology

Seismological Laboratory

1200 E. California Boulevard, MS 252-21

Pasadena, California 91125

hanyue@gps.caltech.edu

ampuero@gps.caltech.edu

(H.Y., J.-P.A.)

Manuscript received 8 March 2016; Published Online 26 July 2016 